\title{
EN FILIPINAS PERVIVEN MUCHOS ASPECTOS DE LA VIDA ESPAÑOLA
}

\section{PHILIPPINE SURVIVES MANY ASPECTS OF SPANISH LIFE}

\section{AUTORA}

\section{Isabel Caro Wilson.}

Excma. Sra. Embajadora de Filipinas en España (Filipinas)

i.carowilson@hotmail.com

\section{RESUMEN}

La independencia de Filipinas, el llamado "desastre del 98" para España, supuso para este país la asimilación de los mejores aspectos de la cultura española para su posterior mezcla con sus propias costumbres. Desde su independencia, fruto de la afirmación un pueblo, Filipinas ha pasado por determinados hechos históricos que le han supuesto un retraso en su camino hacia el desarrollo. Sin embargo, actualmente está viendo cierto progreso económico como resultado de su determinación, haciendo que se le apode como "el tigre de la región".

\section{PALABRAS CLAVE}

Filipinas - Independencia - España - Costumbres - Economía.

\section{ABSTRACT}

The independence of the Philippines, the "disaster of 98" for Spain, accounted the assimilation of the best aspects of Spanish culture for this country, subsequenting a mixing with their own customs. Since independence, being the result of a people's claim, the Philippines has gone through certain historical facts. This facts that have led to a delay in its development path. However, now, is realizing some economic 
progress as a result of its determination. This is the reason because the Philippines are nicknamed "the tiger of the region."

\section{KEY WORDS}

Philippines - Independence - Spain - Customs - Economics.

\section{ÍNDICE}

1. Introducción.

2. Conclusiones.

\section{Introducción}

Al agradecer la amable invitación para que intervenga en estas jornadas, debo hacer patente así mismo el agradecimiento de mi gobierno y del pueblo de Filipinas por la atención que, en esta ocasión, se dispensa a aquel lejano archipiélago, un tiempo florón de la Corona de España. Al abordar la problemática del centenario del '98, con frecuencia se piensa más en Cuba y Puerto Rico, descuidando, a mi juicio, el hecho indudable que fue en Filipinas donde tan significativa efemérides encontró su culmen.

No me incumbe enjuiciar este episodio histórico desde la vertiente española. Como filipina me corresponde valorarlo a la luz de los acontecimientos patrios que supusieron el ocaso definitivo del régimen político español en Filipinas y el estreno de la primera república independiente en el Extremo Oriento. Que, luego, ésta quedara truncada por la intervención de una tercera potencia, en nada amengua su importancia y validez, porque, al correr de los años, sin perder nunca el hilo de la evolución política, Filipinas, a la postre recupera su soberanía y es, en los momentos presentes, un pueblo libre e independiente que surgiendo de las cenizas de una 
guerra cruel y una ocupación enemiga y recientemente de una dictadura tiránica, marcha adelante por la senda del progreso socioeconómico en aquel rincón del globo para admiración de propios y extraños.

Antes de internarme en esa realidad del nuevo ' 98 , es decir, de este año en la antevíspera de un nuevo siglo, permitidme unas brevísimas palabras que se me agolpan cuando de todas partes percibo un casi unánime clamor por denostar el otro '98, cuyo centenario se conmemora en nuestros días, titulándolo de "desastre". Entiendo que sólo puede hablarse de tal si España pretendía que sus posesiones de Ultramar, incluía Filipinas, fueran parte integrante de su territorio nacional y componentes de una patria común. La separación de las mismas, desde luego, habría supuesto un desastre sobrevenido a la unidad de España. Más, los hechos nos manifiestan que dichas posesiones se tenían por "colonias"; es decir, territorios bajo tutela, a los que había que ayudar a desarrollarse y uncir su carro al de la civilización y la cultura mundiales.

En este caso, la emancipación de los mismos no debe interpretarse como tragedia de desunión. Antes al contrario, debe ser motivo de satisfacción, al comprobar que esa separación de las colonias venía de la afirmación de una mayoría de edad y la prueba inequívoca de que la labor de España había fructificado tal y como ella debía pretender. Todo buen padre de familia no se lamenta, culpándose incluso, si el hijo, llegado a la mayoría de edad, contrae matrimonio y, emancipado, construye su propio hogar. Por el contrario, esta coyuntura es motivo de orgullo y satisfacción, porque hace evidente el éxito de la misma cumplida.

Así entendemos los filipinos los sucesos del '98. Para nosotros es la cima de un proceso trisecular, convivencia fil-hispano, durante la cual, a la vez que aportábamos a España territorio y recursos que afianzaron su prestigio y poderío mundiales, asimilábamos lo mejor de su cultura y civilización, que nos disponía para ocupar dignamente un sitial en el concierto de las naciones libres. De ahí que, en este 
centenario, a Filipinas no le duelan prendas $y$, sin rodeos ni disimulos, reconoce cuanto debe a España y muestra su gratitud por la benéfica influencia que ejerciera en nuestra historia nacional.

Sobre esos cimientos sólidos que nos proporcionan la historia, Filipinas ha sabido responder al llamado de su vocación como país como soberano e independiente en el Sudeste asiático. De la mano de sus dirigentes y con el apoyo inteligente del pueblo, Filipinas ha conseguido, no sin esfuerzo y celo patriótico, manumitirse de la dependencia económica, con su impacto político, de la hegemonía de los Estados Unidos. Con ojo avizor y pulso firme, mi país ha logrado diversificar sus mercados, establecer la adecuada competitividad de sus productos y su tecnología, proporcionar los justos alicientes al capital extranjero que aseguren inversiones cabalmente satisfactorias para Filipinas y los demás países inversores. Mientras que se han estancado las economías de los países vecinos, Filipinas consiguió el año pasado un crecimiento del 7,1 por ciento, despojándose de aquel apodo "el enfermo de Asia" para convertirse en el nuevo tigre de la región. Al mismo tiempo, hemos logrado el acuerdo de paz definitiva con los rebeldes musulmanes y el referido al de la guerrilla comunista está en su fase final de negociación. El proceso democrático instaurado por la ex-Presidente Corazón Aquino se vio firmemente establecido durante este mandato del actual Presidente Fidel Ramos, quién ha demostrado con estos hechos que el desarrollo socio-económico de un país, si que es posible y factible dentro del marco de la democracia.

\section{Conclusiones}

Hago votos porque mi modesta exposición sirva para que tanto en el terreno económico como en el social, histórico y cultural, los españoles tornen la mirada a Filipinas, donde -como una intervención aquí programada lo hará manifiesto- todavía perviven mil y un aspectos de la vida y la esencia españolas, ineludible consecuencia de tantos siglos de fraternal unión entre españoles y filipinos, con sus dosis de 
malentendidos, caprichos e imposiciones pero, también con sus desbordamientos de desprendimiento, generosidad y sacrificio. La distanciación de nuestros dos pueblos ha cumplido ya su periplo. Ha sonado la hora de la aproximación. Ojalá que en un futuro cercano y con cierta periodicidad estable, se inicie el trasiego de filipinos y españoles de una a otra dirección en misión de un acercamiento y entendimiento, que, abrazando corazones e identificando pensamientos, podamos contribuir a la universal comprensión de los hombres, porque sólo así podrían imponerse en el panorama mundial los detalles luminosos de una paz vigorosa y permanente. 